\title{
Molecular detection and phylogenetic analysis of Marek's disease virus oncogenes from vaccinated flocks in southern India reveals circulation of very virulent MDV genotype
}

\author{
Kannaki Ramasamy ${ }^{1}$, E. Priyanka ${ }^{1}$, Y. Nishitha ${ }^{2}$, S. Vamshi Krishna ${ }^{2}$, Santosh Haunshi ${ }^{1}$, \\ and Madhuri Subbiah ${ }^{3}$ \\ ${ }^{1}$ Directorate of Poultry Research \\ ${ }^{2}$ Sri PV Narasimha Rao Telangana State Veterinary University \\ ${ }^{3}$ National Institute of Animal Biotechnology
}

June 6, 2021

\begin{abstract}
Marek's disease (MD) is a re-emerging viral disease of chicken and a serious economic threat to poultry industry worldwide. Continuous surveillance with molecular investigation is mandatory to monitor the emergence of virulent MDV strains and to devise any appropriate vaccination strategy and implement bio-security programs. In the present study, we investigated the cases of MD outbreaks in vaccinated poultry flocks. The MD outbreak was confirmed through necropsy (majorily visceral tumors), histopathology and viral gene specific PCR. The pathotypes of the field MDV strains were assessed by molecular analysis of three oncogenes -Meq, pp38 and vIL-8. The Meq sequence of the field strains analyzed in this study lacked the 59 aa unique to mild strains indicating that they are virulent strains. Mutation at position 71 and presence of five proline rich repeats in the transactivation domain, both associated with virulence were observed in these strains, however, the signature sequences specific to very virulent plus strains were absent. Phylogenetic analysis of Meq gene sequences revealed clustering of the field strains with North Indian strains and with a very virulent plus ATE 2539 strain from Hungary. Analyses of pp38 protein at positions 107 and 109 and vIL-8 protein at positions 4 and 31 showed signatures of virulence. Sequence and phylogenetic analysis of oncogenes from field MDVs from vaccinated flock indicated these strains possessing molecular features of very virulent strains. Our data shows here that Meq, vIL-8 and pp38 genes can be used as markers for molecular analysis to decipher the pathotype of MDV strains. Our present study suggests evolution of virulent MDV induced by vaccination.
\end{abstract}

Title: Molecular detection and phylogenetic analysis of Marek's disease virus oncogenes from vaccinated flocks in southern India reveals circulation of very virulent MDV genotype

Running title: Very virulent MDV in Southern India

\section{Authors:}

T. R. Kannaki ${ }^{1 *}$, E. Priyanka ${ }^{1}$, Y. Nishitha ${ }^{2}$, S. Vamshi Krishna ${ }^{2}$, Santosh Haunshi ${ }^{1}$ and Madhuri Subbiah ${ }^{3}$

\section{Affiliations:}

1-ICAR-Directorate of Poultry Research, Hyderabad 500030, Telangana, India

2- Department of Veterinary Microbiology, P. V. Narasimha Rao Telangana Veterinary University, Hyderabad 500030, Telangana, India

3- National Institute of Animal Biotechnology, Hyderabad 500049, Telangana, India 
1* Corresponding author; trkannaki@gmail.com

\section{SUMMARY}

Marek's disease (MD) is a re-emerging viral disease of chicken and a serious economic threat to poultry industry worldwide. Continuous surveillance with molecular investigation is mandatory to monitor the emergence of virulent MDV strains and to devise any appropriate vaccination strategy and implement biosecurity programs. In the present study, we investigated the cases of MD outbreaks in vaccinated poultry flocks. The MD outbreak was confirmed through necropsy (majorily visceral tumors), histopathology and viral gene specific PCR. The pathotypes of the field MDV strains were assessed by molecular analysis of three oncogenes -Meq, pp38 and vIL-8. The Meq sequence of the field strains analyzed in this study lacked the 59 aa unique to mild strains indicating that they are virulent strains. Mutation at position 71 and presence of five proline rich repeats in the transactivation domain, both associated with virulence were observed in these strains, however, the signature sequences specific to very virulent plus strains were absent. Phylogenetic analysis of Meq gene sequences revealed clustering of the field strains with North Indian strains and with a very virulent plus ATE 2539 strain from Hungary. Analyses of pp38 protein at positions 107 and 109 and vIL-8 protein at positions 4 and 31 showed signatures of virulence. Sequence and phylogenetic analysis of oncogenes from field MDVs from vaccinated flock indicated these strains possessing molecular features of very virulent strains. Our data shows here that Meq, vIL-8 and pp38 genes can be used as markers for molecular analysis to decipher the pathotype of MDV strains. Our present study suggests evolution of virulent MDV induced by vaccination.

\section{KEY WORDS:}

Marek's disease virus (MDV), oncogenes, phylogenetics, $M e q$

\section{INTRODUCTION}

Marek's disease (MD) causes huge economic impact by directly causing significant levels of mortality due to visceral lymphomas. In addition, the sub-clinical immunosuppression induced by virulent strains also cause production loss indirectly (Gimeno, 2014). The Marek's disease virus (MDV), classified as gallid alphaherpes virus 2 (GaHV-2), belongs to the genus Mardivirus of the subfamily Alphaherpesvirinae, family Herpesviridae (International Committee on Taxonomy of Viruses, 2017). MDV has been divided into three serotypes as serotype -1, -2 and -3 (Bulow and Biggs, 1975). Of these three serotypes, MDV-1 includes all oncogenic strains, whereas serotype 2 and 3 includes non-oncogenic and avirulent strains, respectively (Witter et al., 2005). The virulence of the MDV-1 has been shifted from mild (m) to virulent (v), very virulent (vv) and very virulent plus $(\mathrm{vv}+)$ over a period due to mutations and positive selection (Witter, 1997; Gimeno and Schat, 2018).

Although the disease is effectively controlled by vaccination and bio-security measures, outbreaks due to emerging virulent strains are observed in recent times worldwide including India (Nair, 2018). In India, both monovalent (serotype 3/ HVT) and bivalent (serotype 2 SB1/ SB303 \& serotype 3/ HVT) are currently used in commercial layers and breeder flock. Despite intensive vaccination, outbreaks in vaccinated flocks are noticed in different parts of dense poultry rearing zones (Suresh et al., 2015; Gupta et al., 2016; Prathiba et al., 2018; Puro et al., 2018). Various factors are involved in the MD outbreaks of vaccinated flocks including faulty vaccination procedure, mycotoxin in feed and concurrent immunosuppressive diseases etc. Emerging virulent strains due to high mutation rates in oncogenes being one of the major factors among them.

Although in vivo pathogenicity studies are mandatory to ascertain the pathotype of emerging MDV strains (Witter et al., 2005; Dudnikova et al., 2007), the assays are tedious and complex. On the other hand, molecular analysis of certain marker genes specifically Meqoncogene has been proved valuable by recent studies (Mescolini et al., 2019). Some of the unique oncogenes namely Marek's EcoRI-Q encoded protein - Meq (Jones et al., 1992), phosphoprotein-pp38(Cui et al., 1999) and vIL- 8 (viral interleukin-8) (Parcell et al., 2001) were associated with oncogenicity and pathogenicity. Their potential as pathotype markers has been demonstrated successfully by recent workers in emerging field strains from several countries viz., 
China (Tian et al., 2011), USA (Padhi and Parcell, 2016), Colombia (Lopez-Osorio et al., 2017) Japan (Abd-Ellatieff et al., 2018) and Italy (Mescolini et al., 2019).

In the present study, we investigated the Indian MDV field strains from MD visceral tumors occurred in vaccinated poultry breeder flocks and analyzed three oncogenes viz., Meq, pp38 and vIL- 8 of 17 MDVs to ascertain their virulence pathotype.

\section{MATERIALS AND METHODS}

\subsection{Sample collection}

Tissue samples were collected between 2017 and 2018 from 13 flocks of different layer/ broiler parent lines/breeds maintained at ICAR-Directorate of Poultry Research (DPR), Hyderabad, India. The parent flocks were used in the production of layer/ broiler or dual type-colored varieties suitable for backyard poultry rearing. All the flocks were vaccinated with HVT on day old at in-house hatchery. Deceased birds from different flocks presented for necropsy showed MD specific lesions like enlargement of liver, spleen and visceral tumors etc. All tumor-associated organs including liver, spleen, kidney, proventriculus and sciatic nerve were collected from MD suspected birds in $10 \%$ neutral buffered formalin for histopathological examination. Another set was collected and kept frozen at $-20 @ \mathrm{C}$ until use for DNA extraction and subsequent use in PCRs. Sample details of the present study are provided in supplementary table 1.

\subsection{Histopathological examination}

The tissues in $10 \%$ neutral buffered formalin were processed for histopathological tissue section and preparation of slides as per the standard protocol. The tissue sections were stained by H\&E stain and visualized under light microscope.

\subsection{Genomic DNA extraction}

Tissue samples were used for DNA extraction by standard procedure. Briefly, the samples were lysed in lysis buffer, extracted with phenol-chloroform-isoamyl alcohol (25:24:1) twice, followed by precipitation of DNA with absolute isopropanol, washed with $70 \%$ ethanol, dried at room temperature and resuspended in nuclease-free water.

\subsection{Screening of samples for MD by PCR}

The samples were screened for MD using genomic DNA extracted by PCR. Meq gene specific PCR targeting BamH1-H 132 bp tandom repeats by using M1 \& M2 primers described previously by Davidson and Borenstein (1999) was employed (Supplementary Table 2). Briefly, the PCR amplification was carried out using $2 \mu \mathrm{l}$ of template DNA in a total volume of $25 \mu \mathrm{l}$ reaction volume containing $2.5 \mu \mathrm{l}$ of $10 \mathrm{x}$ Taq buffer with $\mathrm{MgCl}_{2}, 1 \mu \mathrm{l}$ of each primer $(20 \mathrm{pmol}), 0.5 \mu \mathrm{l}(10 \mathrm{mMol})$ of dNTPs and $0.25 \mu \mathrm{l}(5 \mathrm{U} / \mathrm{ml})$ of Taq DNA polymerase and nuclease free water. The PCR conditions were as follows: $94 @ \mathrm{C}$ for $4 \mathrm{~min}$, 35 cycles of $94 @ \mathrm{C}$ for $1 \mathrm{~min}, 55 @ \mathrm{C}$ for $1 \mathrm{~min}, 72 @ \mathrm{C}$ for $1 \mathrm{~min}$ and final elongation at $72 @ \mathrm{C}$ for $10 \mathrm{~min}$. The presence of $434 \mathrm{bp}$ product after amplification in the samples were considered MD positive and these samples were used for further amplification of MD oncogenes.

\subsection{PCR amplification of MDV oncogenes and sequencing}

Out of $120 \mathrm{MD}$ suspected tissue samples investigated from 13 flocks, 17 samples from 5 flocks were found to be MD positive by Meq gene specific PCR. MD positive samples were used for the amplification of MDV oncogenes, Meq, vIL-8 and pp38. The primer sequences used are provided in supplementary Table 2. The PCR amplification of Meq and vIL-8 genes were carried out as previously described with slight modifications (Tian et al., 2011). The PCR amplification was carried out using $4 \mu$ of template DNA in a total volume of $50 \mu \mathrm{l}$ reaction volume containing $5 \mu \mathrm{l}$ of $10 \mathrm{x}$ Taq buffer with $\mathrm{MgCl}_{2}, 2 \mu \mathrm{l}$ of each primer $(20 \mathrm{pmol}), 1 \mu \mathrm{l}(10$ $\mathrm{mMol})$ of dNTPs and $0.5 \mu \mathrm{l}(5 \mathrm{U} / \mathrm{ml})$ of Taq DNA polymerase and nuclease free water. The PCR conditions for Meq and vIL- 8 were as follows: $94 @ \mathrm{C}$ for $4 \mathrm{~min}, 35$ cycles of $94 @ \mathrm{C}$ for $1 \mathrm{~min}, 56 @ \mathrm{C}$ for $1 \mathrm{~min}, 72 @ \mathrm{C}$ for $1 \mathrm{~min}$ and final elongation at $72 @ \mathrm{C}$ for $10 \mathrm{~min}$. PCR amplification of pp38 gene was carried out as per the 
method of Zhuang et al. (2015). The amplified products were checked in 1.5\% agarose gel and PCR product was purified. The products were sequenced by Sanger sequencing. The obtained sequences were edited and aligned in EditSeq and MegAlign program of DNAStar software. The sequences of the field MDV strains were submitted to NCBI database (Table 1).

\subsection{Sequence and Phylogenetic analysis}

The nucleotide gene sequences of Meq, pp3 and vIL-8 of all MDV strains were subjected to blast analysis by using NCBI BLAST tool (https: blast.ncbi.nlm.nih.gov/Blast.cgi) and compared with other MDV strains available in public domain. A total of 97 sequences including 54 Meq, 25 pp38 and 18 vIL-8 reference gene sequences of MDV of different pathotypes were retrieved for analysis (supplementary Table 3). The sequences along with those of the present study were aligned by CLUSTAL $\mathrm{W}$ and annotated using MEGA X version 10.0.5 (www.megasoftware.net) (Kumar et al., 2018). The best-fit model was selected by comparing the Bayesian information criterion (BIC) scores. Phylogenetic tree was constructed separately for each of three genes by using Neighbor-joining method with 1000 bootstrap replicates based on Tamura-Nei model (Tamura and Nei, 1993). All positions containing gaps and missing data were eliminated.

\section{RESULTS}

\subsection{Gross lesions and Histopathology}

Grossly, in most of the cases presented for necropsy, discrete grayish white nodules of various sizes were observed predominantly in liver and spleen and less commonly in heart, lungs, proventriculus and mesentery. Enlargement of liver and spleen were invariably present. None of the MD suspected carcasses showed enlargement or loss of striation in sciatic nerve. Histopathological examination showed extensive infiltration with pleomorphic cells and lymphocytes.

\subsection{Screening of samples by PCR}

Out of 120 MD suspected tissue samples investigated from 13 flocks, 17 samples from 5 flocks were found to be MD positive by Meq gene specific PCR and histopathology. The age of the flocks during MD outbreak ranged from 14-65 weeks. The outbreak occurred in seven colored broiler breeder, six Aseel - (native chicken) breeder parent, three White Leghorn layer breeder and one Vanaraja, backyard dual purpose variety.

\subsection{Sequencing of oncogenes and Sequence analysis}

Atleast one oncogene was amplified and sequenced for each of the 17 MDV positive samples, a total of 13 Meq, 11 pp38 and 13 vIL-8 gene sequences were sequenced. The obtained sequences were deposited in GenBank with accession numbers. The details are given in Table 1.

The Meq sequences analysis of the current field MDV strains showed $99.8-100 \%$ and $99.5-100 \%$ similarity at nucleotide and amino acid levels, respectively. All strains showed a meq gene length of 1020 bp encoding for meq protein comprising of 339 aa. In the present study, five proline rich repeats (PPPPs) were observed at positions 152-155, 175-178, 191-194, 216-219 and 232-235 in all these strains. The amino acid mutations in the Meq displayed similarity at several positions including $71,77,80,88,93,119,139,153,176,180$, 217, 277, 283, 320 and 326. Two mutations associated with MDV virulence were observed in all 13 Meq sequences at positions 71 (Alanine) and 80 (Tyrosine). Four distinctive substitutions including one in basic region and three in leucine zipper domain were observed in all sequences except one (MK388077) as follows: 80 Y (Tyrosine; D80Y), 88 T (threonine; A88T), 93 R (arginine; Q93R) and 139 A (alanine; T139A) (Table 2).

As for pp38 gene, the identity ranged from 98.6 - $99.9 \%$ and $98.6-100 \%$ at nucleotide and amino acid levels, respectively among the field MDV sequences. 11 sequences of this study were compared with five reference MDVs at amino acid levels. The analysis revealed mutation at aminoacid position109 (glutamate-glycine). All the 11 sequences had glutamine at position 107 (Table 3).

vIL-8 comprises of 132 amino acids encoded by 682 nucleotides from three exons $(1 . .64,240 . .375,474 . .678)$. 
The homology of the nucleotide and deduced amino acid sequences of 13 sequences were $99.5-100 \%$ and $100 \%$ respectively. The complete nucleotide and amino acid sequences of five reference MDVs were compared with the sequences of the present study. All the 13 sequences had two mutations at nucleotide position 11 ( $\mathrm{T}-\mathrm{C}$ ) and 92 (A-G) resulting in amino acid substitutions at positions 4 (leucine to serine; L4S) and 31 (aspartate to glycine; D31G) (Table 4).

\subsection{Phylogenetic analysis}

Phylogenetic tree of Meq gene sequences with other reference sequences revealed that all the current strains (except one -002 MDV strain) clustered together with earlier reported Indian strains from northern part of the country and with very virulent plus ( $\mathrm{vv}+$ ) ATE 2539 strain from Hungary (Fig. 1). One MDV strain (MK388077) of present study clustered closely with two Italian strains (MK139661 and MK139672). Two Indian MDV strains TNN1 (HM749324) and TNN2 (HM749325) reported earlier from southern part clustered away from present strains.

The phylogenetic tree of pp38 gene showed clustering of the current 11 MDV field strains with other Indian strains from north and southern part of the country. It also clustered with two Chinese strains DY04 (HQ638161) and XJ03 (HQ638175). The other cluster included vaccine strains, mild (m), virulent (v) and very virulent (vv) strains (Fig. 2).

The phylogenetic tree of the vIL-8 gene showed that all 13 sequences of present study clustered with very virulent (vv) and very virulent plus (vv+) strains from USA and one strain from China. The sequences of other Indian strains from Southern part also fell on the same cluster. Mild and vaccine MDV strain formed a separate cluster (Fig. 3).

\section{DISCUSSION}

Marek's disease (MD) is one of the re-emerging viral diseases of poultry causing serious economic threat to poultry industry (Schat and Nair, 2013). Although vaccines provide strong immunity and highly effective against clinical disease, outbreaks in vaccinated flocks are not uncommon. More virulent and pathogenic MDVs are evolving in recent times worldwide including India. The disease has shifted to visceral lymphomas rather than neural form in recent outbreaks (Kannaki et al., 2020). Moreover, the sub-clinical infection of young chicks with immunosuppressive diseases such as Chicken infectious anemia (CIA), infectious bursal disease (IBD) and fowl adeno virus (FAV) also attribute to the MD outbreaks in vaccinated flocks due to vaccination failure induced by immunosuppression. Some of the unique oncogenes of serotype I MDVs are associated with viral oncogenicity and pathogenicity. In the present study, we investigated the three oncogenes Meq, pp38 and vIL-8 of 17 MDV field strains from MD visceral tumors occurred in vaccinated poultry breeder flocks.

The nucleotide similarity of present MDV strains ranged from $98.5-100 \%$ for all three oncogenes due to point mutation at various positions. Although all strains are from same location, the variation may be attributed to high mutation capacity of the field MDVs. Different age groups and genetic background, production type (layer breeder, broiler breeder and native breed), other vaccines and vaccine immunity could be other factors that might have attributed for the emergence of virulent MDV strains.

Meq gene of vv and vv+ MDV pathotypes encode for 339 amino acid containing a N-terminal basic leucine zipper (bZIP) transactivation domain and C-terminal proline rich trans-repression domain. Dimerization and activation of transactivation domain leads to cell transformation and subsequent tumorigenesis (Liu et al., 1999; Levy et al., 2003). Meq of mild or vaccine strains such as CVI988, CU-2 or JM have 59 aa insertion in the C-terminal region known to have suppression effect on the Meq expression and oncogenicity (Shamblin et al., 2004; Chang et al., 2002). Meq of all field MDVs investigated here are of 339 aa length encoded by 1020 bp coding sequence indicating that they are virulent strains. Moreover, the amino acid changes at position 71 and 77, are considered as feature of high virulence MDVs (Shamblin et al., 2004). Mutation at 71 was observed in all current field strains. However, at 77 was not present like Chinese and other field strains (Tian et al., 2011). Mutation at 77 seems to be a feature of virulent strains of USA (Tian et al., 2011). The three 
amino acid substitutions at positions 119, 153 and 156 unique to very virulent plus strains like 584A and $648 \mathrm{~A}$ were not present in current strains giving indication that they have not yet evolved as vv + . However, some unique mutations at positions 80 (D80Y), 88 (A88T), 93 (Q93R) and 139 (T139A) were observed in the field strains. Unique amino acid substitutions in $\mathrm{Meq}$ gene are recently reported in MDV field strains circulating in Italy (Mescolini et al., 2019), China (Yu et al., 2013), Colombia (Lopez-Osorio et al., 2017) and Turkey (Ozan et al., 2021). Geographically restricted independent evolution of field strains was observed in vaccinated flocks. In the present study also, three unique amino acid substitutions are observed in the field MDV strains. These unique mutations are also observed in few other field strains reported from different regions of this country. Previous studies show the regularity in the mutations of Meqgenes of MDVs from outbreaks of increased virulence (Zhang et al., 2011). Although of GaHV-2 is a DNA virus, Meq gene of GaHV-2 has high mutation frequency of approximately $10^{-4}$ substitutions per year like that of RNA viruses (Padhi and Parcells, 2016). High mutation frequency combined with positive selection in vaccinated flocks could drive the emergence of highly virulent pathotypes. However, it needs to be ascertained whether these attribute to a continuing evolutionary drift leading to increased virulence of MDV strains circulating in India.

Number of proline repeats is strongly associated with the level of MDV virulence (Renz et al., 2012; Shamblin et al., 2014). Negative correlation exists between their number and the virulence. The number of four proline repeats ranges between 2-8 in all MDV strains. Generally, virulent to very virulent MDV strains have been shown to possess 5 'PPPP' repeats in Meq gene (Abdallah et al., 2018; Mescolini et al., 2019). All the current strains had 5 repeats. Earlier reported MDV strains from India with virulent to very virulent pathotype also possessed 4-5 'PPPP' repeats (Kalyani et al., 2010; Prathibha et al., 2018). Phylogenetic analysis revealed that current strains clustered with Indian strain from northern part and with very virulent plus ATE 2539 strain from Hungary. Surprisingly, the current strains clustered away from earlier very virulent strains from southern India reported a decade ago (TNN1 \& TNN2).

The pp38 gene encodes a $38 \mathrm{kDa}$ phosphoprotein that has a role in cell transformation and virus reactivation from latency (Gimeno et al., 2005). Minor variations were observed in amino acid substitutions among the field strains. Glutamine at position 107 is conserved among virulent MDVs except for CVI988 vaccine strain wherein it has arginine instead of glutamine. The mutation at 107 is considered a reliable biomarker for differentiating field strains from CVI988 vaccine (Baigent et al., 2016). Glutamate at position 109 present in very virulent and $\mathrm{vv}+$ strains was observed in 5 out of 11 sequences investigated. Both these positions viz. $107 \& 109$ can be considered as virulence indicators as observed earlier in the virulent strains of USA and China (Shamblin et al., 2004; Tian et al., 2011).

The vIL- 8 gene consists of 3 exons and encodes 134 aa length peptide that is expressed during cytolytic infection and shows closest homology to mammalian and avian IL-8 (Cui et al., 2004). vIL-8 is considered important for switch of infection from B to T lymphocytes (Schat and Xing, 2000). This gene was shown to be highly conserved among different pathotypes, hence change in virulence can be strongly speculated with any mutations within the gene. The two-point mutations at positions 4 (L4S) and 31 (D31G), initially considered as unique to Chinese MDV strains (Tian et al., 2011) are observed in the current study as well. These mutations were observed in other field strains from Japan and India (Abd-Ellatieff et al., 2018; Prathibha et al., 2018). The phylogenetic tree of the vIL-8 gene revealed the clustering of present strains with vv and vv+ strains from USA and China indicating the virulence of present strains.

Our present study supports the argument that the vaccination pressure imposed the genetic drift of emerging strains towards virulence (Wozniakowski and Salamonowicz, 2014; Padhi and Parcell, 2016; Nair, 2018). Sequence and phylogenetic analyses of oncogenes from field MDVs from vaccinated flock indicate these strains possess molecular features of very virulent strains. Although vv + strains are not yet reported in Indian poultry flocks and not observed in the current investigation, the rate of evolution of Meq gene in recent times by various reports suggest the rapid evolution in MDV strains towards severe pathogenicity. Meq gene followed by vIL- 8 and pp38 genes could be of additional value in deciphering the pathotype of MDV strains. Molecular characterization of oncogenes would be the most rapid, reliable and affordable method to 
suggest the virulence of field strain instead of tedious in vivopathotyping assays. In conclusion, continuous surveillance is mandatory to monitor the emergence of virulent MDV strains and to devise appropriate vaccination strategy and bio-security programs.

\section{COMPETING INTERESTS}

The authors declare that they have no competing interests.

\section{ACKNOWLEDGEMENTS}

This work was supported by ICAR-DPR Institute funding for research projects.

\section{AUTHOR CONTRIBUTIONS}

TRK ${ }^{1}$ Conceived the study and collected the samples. $\mathrm{EP}^{1}$ and $\mathrm{YN}^{2}$ carried out PCR work and sequencing. TRK $^{1}$ and $\mathrm{MS}^{3}$ carried out sequence analysis and phylogenetic analysis. TRK ${ }^{1}$ prepared the manuscript and $\mathrm{SH}^{1}$ and $\mathrm{MS}^{3}$ critically reviewed the manuscript. All authors have read and approved the manuscript.

\section{ETHICAL APPOVALS}

This study did not involve any animal subjects. For handling the samples at ICAR-DPR appropriate biosafety measures were followed as per the Institute biosafety guidelines.

\section{Data availability}

Data available in article supplementary material: The data that supports the findings of this study are available in the supplementary material of this article (Supplementary Table 1, 2 and 3).

\section{REFERENCES}

Abdallah, F., Hassanin, O., Attar, E., Ali, H., Megahed, M., \& Nair, V. (2018). Marek's disease virus in Egypt: Historical overview and current research based on the major MDV-encoded oncogene Meq. Hosts and Viruses , 5, 35-43.

Abd-Ellatieff, H. A., Abou Rawash, A. A., Ellakany, H. F., Goda, W. M., Suzuki, T., \& Yanai, T. (2018). Molecular characterization and phylogenetic analysis of a virulent Marek's disease virus field strain in broiler chickens in Japan. Avian Pathology, 47(1), 47-57.

Bulow, V.V., Biggs, P.M. (1975). Differentiation between strains of Marek's disease virus and turkey herpes virus by immunofluorescence assays. Avian Pathology, 4, 133-146.

Chang, K.S., Ohashi, K., Onuma, M., (2002). Suppression of transcription activity of the MEQ protein of oncogenic Marek's disease virus serotype 1 (MDV-1) by L-MEQ of non-oncogenic MDV-1. The Journal of Veterinary Medical Science, 64 (12), 1091-1095.

Cui, X., Lee, L.F., Reed, W.M., Kung, H.J., Reddy, S.M. (2004). Marek's disease virus-encoded vIL-8 gene is involved in early cytolytic infection but dispensable for establishment of latency. Journal of Virology, 78(9):4753-4760.

Cui, Z., Qin, A., Lee, L.F., Wu, P., Kung, H.J. (1999). Construction and characterization of a H19 epitope point mutant of MDV CVI988/Rispens strain. Acta Virologica, 43 (2/3), 169-173.

Davidson, I., Borenstein, R. (1999). Multiple infection of chickens and turkeys with avian oncogenic viruses: prevalence and molecular analysis. Acta Virologica, 43(2-3):136-142.

Dudnikova, E., S. Norkina, A. Vlasov, A. Slobodchuk, L. F. Lee, andR. L. Witter. (2007). Evaluation of Marek's disease field isolatesby the "best fit" pathotyping assay. Avian Pathology, 36:135-143.

Gimeno, I. M. (2014). Marek's Disease and Differential Diagnosis with Other Tumor Viral Diseases of Poultry. In Encyclopedia of Agriculture and Food Systems (pp. 156-171). 
Gimeno, I. M., Schat, K. A. (2018). Virus-induced immunosuppression in chickens. Avian Diseases, 62, $272-285$.

Gimeno, I. M., R. L. Witter, A. M. Fadly, and R. F. Silva. (2005). Novel criteria for the diagnosis of Marek's disease virus-induced lymphomas. Avian Pathology, 34:332-340.

Gupta, M., Deka, D., Ramneek. (2016). Sequence analysis of Meq oncogene among Indian isolates of Marek's disease herpesvirus. Meta Gene,9, 230-236.

International Committee on Taxonomy of Viruses (2017). Master Species List 2017 [WWW Document]. ICTV: Retrieved from https://talk.ictvonline.org/files/master-species-lists/m/msl/7185.

Jones, D., Lee, L., Liu, J. L., Kung, H. J., \& Tillotson, J. K. (1992). Marek's disease virus encodes a basic-leucine zipper gene resembling the fos/jun oncogenes that is highly expressed in lymphoblastoid tumors.Proceedings of the National Academy of Sciences, 89, 4042-4046.

Kannaki T. R., Vasudevan Gowthaman. (2020). Marek's disease: time to review the emerging threat in Indian poultry. World's Poultry Science Journal, 76:1, 91-99.

Kumar, S., Stecher, G., Li, M., Knyaz, C., \& Tamura, K. (2018). MEGA X: Molecular evolutionary genetics analysis across computing platforms. Molecular Biology and Evolution , 35(6), 1547-1549.

Levy, A.M., Gilad, O., Xia, L., Izumiya, Y., Choi, J., Tsalenko, A. (2005). Marek's disease virus: Meq transforms chicken cells via the v-Jun transcriptional cascade: a converging transforming pathway for avian oncoviruses. Proceedings of the National Academy of Sciences of the United States of America. 102(41):148311486 .

Liu, J. L., Lin, S. F., Xia, L., Brunovskis, P., Li, D., Davidson, I., Kung, H.J. (1999). Meq and V-IL8: Cellular genes in disguise? Acta Virologica, 43, 94-101.

López-Osorio, S., Piedrahita, D., Espinal-Restrepo, M.A., Ramírez-Nieto, G.C., Nair, V., Williams, S.M., Baigent, S., Ventura-Polite, C., Aranzazu-Taborda, D.A., Chaparro-Gutiérrez, J.J. (2017). Molecular characterization of Marek's disease virus in a poultry layer farm from Colombia. Poultry Science, 96(6), 1598-1608.

Mescolini, G., Lupini, C., Felice, V., Guerrini, A., Silveira, F., Cecchinato, M., \& Catelli, E. (2019). Molecular characterization of the meq gene of Marek's disease viruses detected in unvaccinated backyard chickens reveals the circulation of low- and high-virulence strains.Poultry Science, 98(8), 3130-3137

Nair, V. (2018). Spotlight on avian pathology: Marek's disease.Avian Pathology, 47, 440-442.

Ozan, Emre, Muftuoğlu, Bahadır, Sahindokuyucu, Ismail, Kuruçay, Hanne, Inal, Sinem, Kuruca, Nilufer, Elhag, Ahmed, Karaca, Efe, Tamer, Cüneyt, Gumusova, Semra, Albayrak, Harun \& Barry, Gerald, Gulbahar, M. Yavuz, Yazici, Zafer. (2021). Marek's disease virus in vaccinated poultry flocks in Turkey: its first isolation with molecular characterization.Archives of Virology , 166. 1-11.

Padhi, A., Parcells, M. S. (2016). Positive selection drives rapid evolution of the meq oncogene of Marek's disease virus. PLoS ONE,11(9), e0162180.

Parcells, M.S., Lin, S.F., Dienglewicz, R.L., Majerciak, V., Robinson, D.R., Chen, H.C., Wu, Z., Dubyak, G.R., Brunovskis, P., Hunt, H.D. (2001). Marek's disease virus (MDV) encodes an interleukin-8 homolog (vIL-8): characterization of the vIL-8 protein and a vIL-8 deletion mutant MDV. Journal of Virology, 75, $5159-5173$.

Prathibha, Y., Sreedevi, B., Vinod Kumar, N., Srilatha, C. (2018). Molecular characterization and phylogenetic analysis of oncogenes from virulent serotype-1 Marek's disease virus in India. Acta Virologica, 62(3), $277-286$.

Puro, K.U., Bhattacharjee, U., Baruah, S., Sen, A., Das, S., Ghatak, S., Doley, S., Sanjukta, R., Shakuntala, I. (2018). Characterization of Marek's disease virus and phylogenetic analyses of meq gene from an outbreak 
in poultry in Meghalaya of Northeast India. Virus disease, 29(2), 167-172.

Renz, K. G., Cooke, J., Clarke, N., Cheetham, B. F., Hussain, Z., Fakhrul, Islam, A. F. M., Walkden-Brown, S. W. (2012). Pathotyping of Australian isolates of Marek's disease virus and association of pathogenicity with meq gene polymorphism. Avian Pathology, 41(2), 161-176.

Schat, K. A., Nair, V. (2013). Neoplastic diseases: Marek's disease. In D. E. Swayne, J. R. Glisson, L. R. McDougald, L. K. Nolan, D. L. Suarez, \& V. L. Nair (Eds.), Diseases of Poultry, 13th ed. (pp. 515-552). Ames, Iowa, USA: Wiley-Blackwell Hoboken

Shamblin, C. E., Greene, N., Arumugaswami, V., Dienglewicz, R. L., \& Parcells, M. S. (2004). Comparative analysis of Marek's disease virus (MDV) glycoprotein-, lytic antigen pp38- and transformation antigen Meqencoding genes: Association of meq mutations with MDVs of high virulence. Veterinary Microbiology, 102(3-4), 147-167.

Suresh, P., Johnson Rajeswar, J., Sukumar, K., Harikrishnan T.J., Srinivasan, P. (2015). Pathotyping of recent Indian field isolates of Marek's disease virus serotype 1. Acta Virologica, 59(2):156-165.

Tamura, K., Nei, M. (1993). Estimation of the number of nucleotide substitutions in the control region of mitochondrial DNA in humans and chimpanzees. Molecular Biology and Evolution, 10(3), 512-526.

Tian, M., Zhao, Y., Lin, Y., Zou, N., Liu, C., Liu, P., Huang, Y. (2011). Comparative analysis of oncogenic genes revealed unique evolutionary features of field Marek's disease virus prevalent in recent years in China. Virology Journal, 8, 121.

Witter, R. L. (1997). Increased virulence of Marek's disease virus field isolates. Avian Diseases , 41(1), 149.

Witter, R. L., Calnek, B. W., Buscaglia, C., Gimeno, I. M., \& Schat, K. A. (2005). Classification of Marek's disease viruses according to pathotype: Philosophy and methodology. Avian Pathology , 34, 75-90.

Woźniakowski, G., \& Samorek-Salamonowicz, E. (2014). Molecular evolution of Marek's disease virus (MDV) field strains in a 40-year time period. Avian Diseases , 58(4), 550-557.

Yu, Z.-H., Man, T., Lou, J., Wang, X.-W., Ding, K., Yu, L.-L., Liu, J.-X. (2013). Molecular characteristics and evolutionary analysis of field Marek's disease virus prevalent in vaccinated chicken flocks in recent years in China. Virus Genes , 47, 282-291.

Zhang, Y. P., Liu, C. J., Zhang, F., Shi, W., Li, J. (2011). Sequence analysis of the meq gene in the predominant Marek's disease virus strains isolated in China during 2006-2008. Virus Genes , 43(3), 353357.

Zhuang, X., Zou, H., Shi, H. (2015). Outbreak of Marek's disease in a vaccinated broiler breeding flock during its peak egg-laying period in China. BMC Veterinary Research 11, 157.

\section{LEGENDS}

Table 1 Details of nucleotide sequences of Meq, pp38 and vIL-8 of field MDVs submitted to GenBank

Table 2 Amino acid substitutions in the Meq protein of field MDV strains compared with reference strains

Table 3 Amino acid substitutions in the pp38 protein of field MDV strains compared with reference strains

Table 4 Amino acid substitutions in the vIL-8 protein of field MDV strains compared with reference strains

Fig. 1 Phylogenetic tree of $M e q$ gene nucleotide sequences of 13 field MDV strains and the 54 reference sequences retrieved from NCBI database 
Phylogenetic tree was constructed with Neighbor-Joining method with 1000 bootstrap replicates using Tamura-nei model in MEGA 10.0.5 software. Strains of this study were highlighted $\left(^{*}\right)$.

Fig. 2 Phylogenetic tree of $p p 38$ gene nucleotide sequences of 11 field MDV strains and the 25 reference sequences retrieved from NCBI database

Phylogenetic tree was constructed with Neighbor-Joining method with 1000 bootstrap replicates using Tamura-nei model in MEGA 10.0.5 software. Strains of this study were highlighted $\left(^{*}\right)$.

Fig. 3 Phylogenetic tree of $v I L-8$ gene nucleotide sequences of 13 field MDV strains and the 18 reference sequences retrieved from NCBI database

Phylogenetic tree was constructed with Neighbor-Joining method with 1000 bootstrap replicates using Tamura-nei model in MEGA 10.0.5 software. Strains of this study were highlighted $(*)$. 


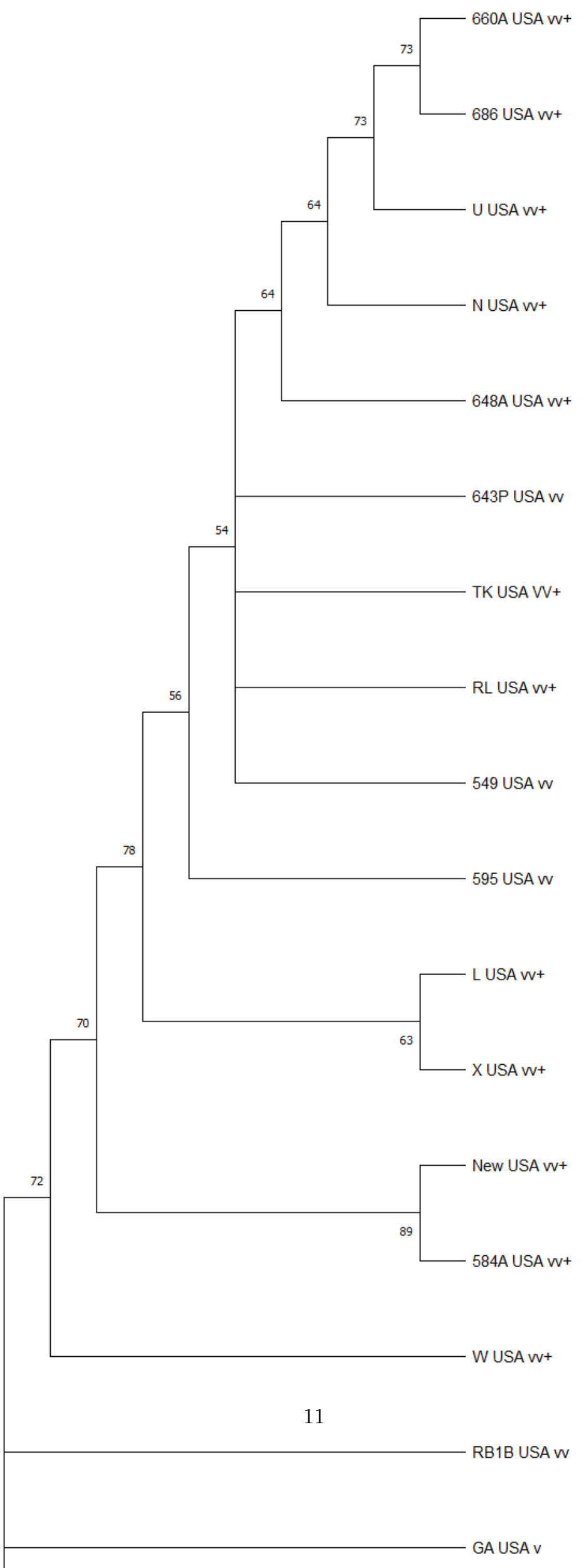




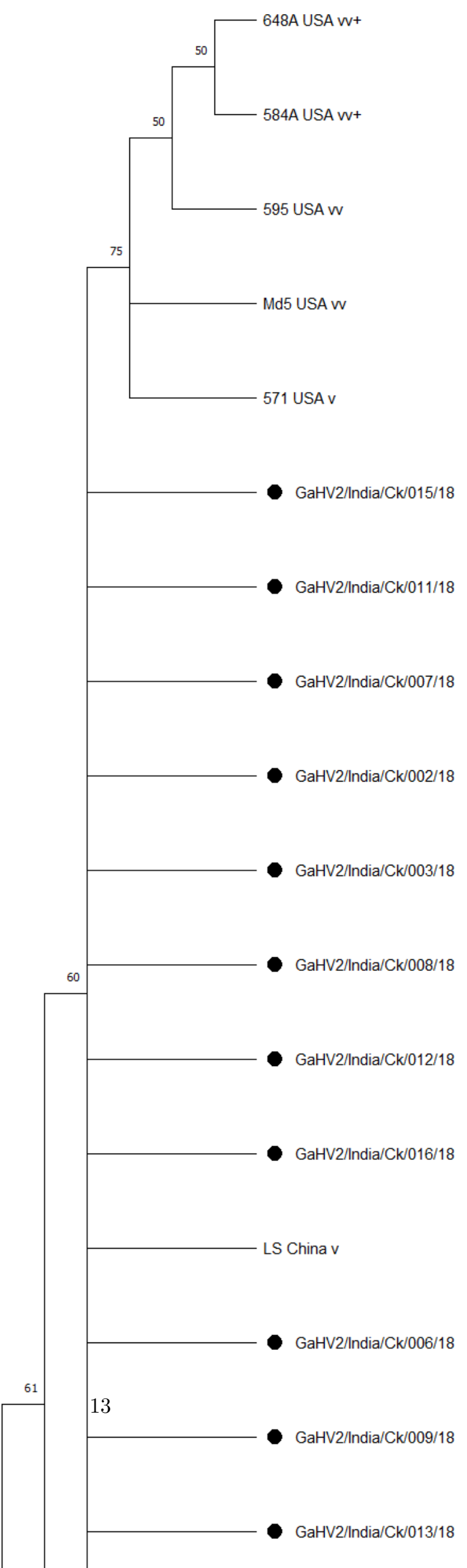




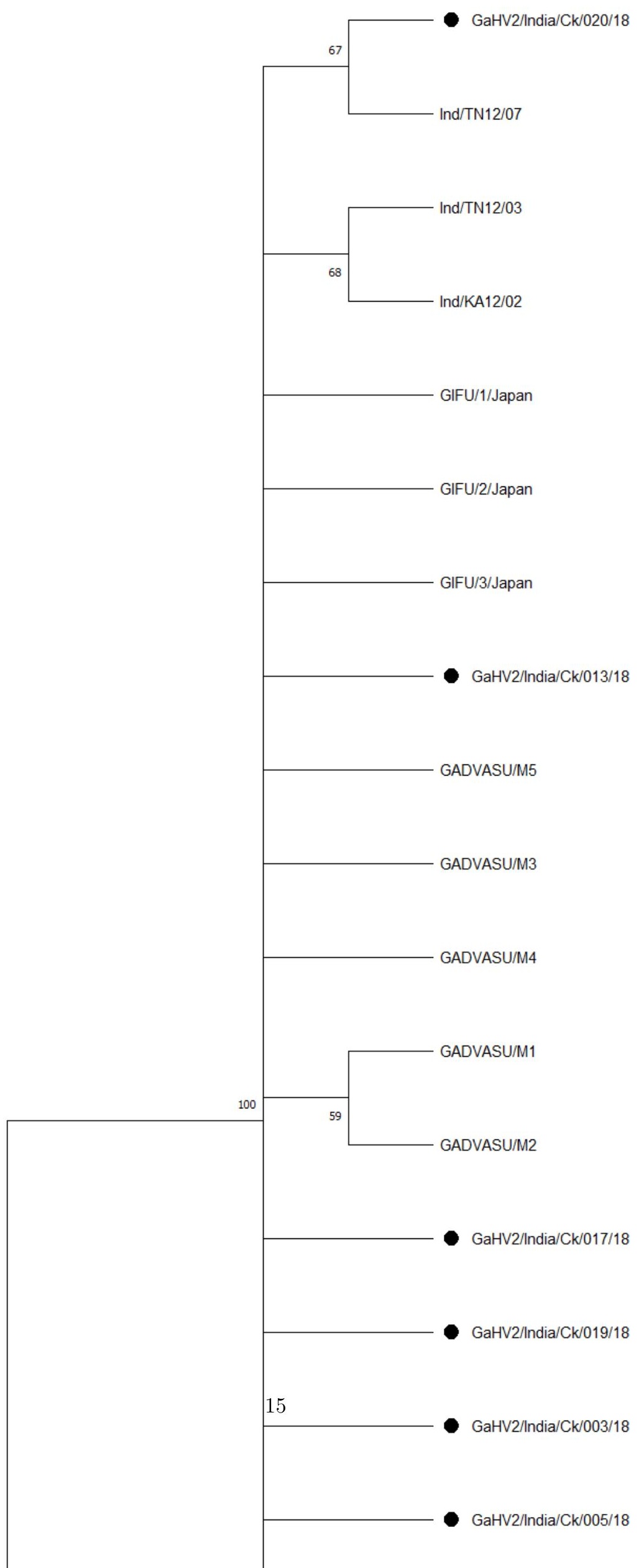




\section{Hosted file}

Table 1 GenBank submission.docx available at https://authorea.com/users/418155/articles/ 525013-molecular-detection-and-phylogenetic-analysis-of-marek-s-disease-virus-oncogenesfrom-vaccinated-flocks-in-southern-india-reveals-circulation-of-very-virulent-mdvgenotype

\section{Hosted file}

Table 2 Meq Protein amino acid.docx available at https://authorea.com/users/418155/articles/ 525013-molecular-detection-and-phylogenetic-analysis-of-marek-s-disease-virus-oncogenesfrom-vaccinated-flocks-in-southern-india-reveals-circulation-of-very-virulent-mdvgenotype

\section{Hosted file}

Table 4 VIL8 amino acid.docx available at https://authorea.com/users/418155/articles/525013molecular-detection-and-phylogenetic-analysis-of-marek-s-disease-virus-oncogenes-fromvaccinated-flocks-in-southern-india-reveals-circulation-of-very-virulent-mdv-genotype

\section{Hosted file}

Table 3 pp38 amino acid.docx available at https://authorea.com/users/418155/articles/525013molecular-detection-and-phylogenetic-analysis-of-marek-s-disease-virus-oncogenes-fromvaccinated-flocks-in-southern-india-reveals-circulation-of-very-virulent-mdv-genotype 